\title{
Weaning from cardiopulmonary bypass
}

\author{
Heezoo Kim \\ Department of Anesthesiology and Pain Medicine, School of Medicine, Korea University, Seoul, Korea
}

The main goal of weaning from cardiopulmonary bypass (CPB) is a smooth transition from mechanical pump-assisted circulation to spontaneous heart activities with sufficient blood flow to maintain systemic circulation. Before initiation of weaning from the CPB, optimal condition for re-beating should be prepared. Normothermia (core temperature $>36^{\circ} \mathrm{C}$ ) is achieved by actively re-warming through the $\mathrm{CPB}$ heat exchanger, active warming devices. However, core temperature should not be exceeded by more than $38^{\circ} \mathrm{C}$ to avoid postoperative neurological dysfunction [1]. The findings of laboratory data should be within normal ranges. Arterial blood gas analysis is carried out to identify oxygen content of the blood as hematocrit $(>25 \%)$, hemoglobin ( $>7 \mathrm{~g} / \mathrm{dl}), \mathrm{PaO}_{2}(>100 \mathrm{mmHg})$ and absence of metabolic, electrolytic disturbances. The anesthesiologists restart sleeping alarms and adjust monitors, ventilator settings and oxygen flows. After aortic declamping, heart re-beat spontaneously in most cases with minor supportive interventions such as electrical defibrillation, pace maker, and small dose of inotropics. Atrial kick contributes more than $20 \%$ of ventricular filling, returning and maintaining of normal sinus rhythm (heart rate between $70-100$ beats per min) is preferable. Electric conversion of supraventricular tachycardia, atrial fibrillation and temporary cardiac pacing for atrioventricular conduction block should be considered. Optimized preload is achieved by volume control, mean arterial pressure maintained within 70-90 mmHg with vasoactive agents. In case of inability to wean from CPB despite preload optimization, global cardiac function and completeness of surgery should be assessed by transesophageal echocardiography (TEE) examination. Most common causes of weaning difficulty are left and/or right ventricular failures and inappropriate vasodilatation. TEE allows diagnostic and therapeutic decision makings, and appropriate treatment option. Routine TEE examinations before terminating the $\mathrm{CPB}$ is essential for detecting unexpected problems such as an iatrogenic aortic dissection from arterial cannulation site or intracardiac thrombus formations even after full heparinization or any other anatomical anomalies $[2,3]$. Because of major complication of TEE probe insertion is the esophageal injury, anesthesiologists carefully manipulate TEE probe, especially patient with an esophageal pathology preoperatively [4]. Faultiness of surgery should be excluded (valvular dysfunction, coronary graft failure, left ventricular outflow obstruction) by TEE examinations, and vasoplegic syndrome managed by vasopressor administration [5]. The recently emerged minimally-invasive hemodynamic monitoring devices can assess the cardiac output, preload, intrathoracic volume and tissue oxygenation which might be guide weaning management with real time inspections of responsiveness of fluid loading and vasoactive agents [6]. Patients with risk factor of ventricular dysfunction (elderly, chronic beta-blocker treatment, renal failure, pulmonary hypertension) tend to be difficult in weaning from $\mathrm{CPB}$, awareness of these risk factors are important for preparing and planning aggressive cardiosupportive management earlier as prophylactic intervention [7]. Protamine sulfate is administrated slowly in order to neutralize generalized heparinization. Thromboelastography as a point-of-care monitoring device can provide rapid information about global hemostatic states (from clot formation, stabilization to fibrinolysis) to achieve goal oriented transfusions during the cardiac operation [8].

Weaning from $\mathrm{CPB}$ is associated with complicated problems and requires multiplinary approaches simultaneously. Accor-

Corresponding author: Heezoo Kim, M.D., Ph.D., Department of Anesthesiology and Pain Medicine, School of Medicine, Korea University, 97, Gurodong-gil, Guro-gu, Seoul 152-703, Korea. Tel: 82-2-2626-3236, Fax: 82-2-851-9897, E-mail: kimheezoo@hotmail.com

(c) This is an open-access article distributed under the terms of the Creative Commons Attribution Non-Commercial License (http:// creativecommons.org/licenses/by-nc/3.0/), which permits unrestricted non-commercial use, distribution, and reproduction in any medium, provided the original work is properly cited. 
ding to observational studies, there were strong correlations between the technical errors and teamwork disruptions caused by poor communication and lack of information during weaning period in cardiac teams [9]. The weaning moment is a critical time for confirming and verifying surgical results and achieving the optimization of hemodynamics. Thus, important information and process should be shared and fully communicated among the anesthesiologist, the cardiac surgeon, and the perfusionist.

\section{References}

1. Grigore AM, Murray CF, Ramakrishna H, Djaiani G. A core review of temperature regimens and neuroprotection during cardiopulmonary bypass: does rewarming rate matter? Anesth Analg 2009; 109: 1741-51.

2. Kim SH, Ryu JS, Kim TY, Yoon TG, Kang W, Song JE. Abrupt formation of intracardiac thrombus during cardiopulmonary bypass with full heparinization -A case report. Korean J Anesthesiol 2012; 62: 175-8.

3. Jung HJ, Kim JB, Im KS, Joo CH, Lee JM. Cardiopulmonary bypass weaning difficulty due to anomalous origin of coronary artery.
Korean J Anesthesiol 2013; 64: 533-5.

4. Lee JY, Jeong DM, Lee SH, Lee SM. Transesophageal echocardiography (TEE)-induced Mallory-Weiss laceration in a patient who underwent aortic and mitral valve replacement -A case report. Korean J Anesthesiol 2010; 59 Suppl: S103-6.

5. Licker M, Diaper J, Cartier V, Ellenberger C, Cikirikcioglu M, Kalangos A, et al. Clinical review: management of weaning from cardiopulmonary bypass after cardiac surgery. Ann Card Anaesth 2012; 15: 206-23.

6. Peyton PJ, Chong SW. Minimally invasive measurement of cardiac output during surgery and critical care: a meta-analysis of accuracy and precision. Anesthesiology 2010; 113: 1220-35.

7. Maganti MD, Rao V, Borger MA, Ivanov J, David TE. Predictors of low cardiac output syndrome after isolated aortic valve surgery. Circulation 2005; 112(9 Suppl): I448-52.

8. Tanaka KA, Bolliger D, Vadlamudi R, Nimmo A. Rotational thromboelastometry (ROTEM)-based coagulation management in cardiac surgery and major trauma. J Cardiothorac Vasc Anesth 2012; 26: 1083-93.

9. Barach P, Johnson JK, Ahmad A, Galvan C, Bognar A, Duncan R, et al. A prospective observational study of human factors, adverse events, and patient outcomes in surgery for pediatric cardiac disease. J Thorac Cardiovasc Surg 2008; 136: 1422-8. 